\title{
Teenagers Perceptions of Retail Format in Shopping Malls: A study on Forum Mall and its Patronage in Bangalore
}

\author{
V Jaykumar*
}

\section{Abstract}

The Indian retail market has grown at a double-digit compound annual growth rate over the last five years and was worth an estimated \$554bn in 2011 and is expected to grow further. The Indian economy grew throughout the global downturn, with increasing consumer purchasing power bolstering the retail sector. Retailing is now the second highest contributor to India's gross domestic product. (PR Newswire, New York, 2012)

\begin{abstract}
"Facebook, Twitter and more have become de rigueur rather than optional for centre marketers,"(Henry, Alison). "Centre owners and managers are also placing renewed emphasis on enhancing the 'experience' of in a bricks and-mortar environment, through targeted promotional events to engage consumers and offer them additional incentives to shop in-mall vs online."The forum mall in Bangalore presents a unique retail pattern site in Bangalore that helps build the brand identity of the mall for teenagers, as they are the ones who like the format. This study explores the relationship between teenager's identity and their perception towards Forum Mall as a blend of lifestyle mall retailing and a patronage pattern. A store intercept survey approach was used to collect data
\end{abstract}

* Professor, Department of Management Studies, PES University, Bengaluru, India; jaykumarv@pes.edu 
from 120 teenagers mostly college and university students. Findings indicated that teenager's identity as a mall enthusiast and/or a habitual mall visitor had little impact on their perceptions about the importance of selected store atmospherics in the decision to shop at Forum mall, Bangalore but did influence some of their intended patronage behaviors towards the mall.

Keywords: Unique retailing, mall atmospherics, store patronage

\section{Introduction}

The Rs 45,000-crore organized retail sector, growing at the rate of $12 \%$, is all set to witness the maximum number of large format malls and branded retail stores in South India, which will be followed by North, West and the East in the next two years. According to Kumar Rajagopalan, chief executive officer, Retailers Association of India (RAI), retail space is cheaper in South India. Retail rentals in the NCR and Mumbai have gone up three times between financial year 2006-07 and 2008-09 compared to the figures in South and East. High rentals naturally come as a disincentive for setting up new retail properties. (Financial Express, New-Delhi, 2009)

"Fuelled by outsourcing from Western companies, India's educated class is getting richer and now has money to spare beyond the basics of food and housing. The people are looking for a little luxury in the form of consumer goods." (Financial Times, London, 2010)

Teens love spending time at the mall with all of its social and material attractions, and retailers certainly view teens as a lucrative market. The teen market is growing in size and spending power (NPD Group, 2010). Teens in the Bangalore spent 6 to 8 percent more in 2013 than they did in 2011. Sales at Forum mall more than tripled between 2008 and 2012, (Kang, 2006; NPD Group, 2010). Retailers that focus specifically on the teen segment reported sales increases of 8 to 10 percent for the first quarter of 2013 when most retailers reported negative or flat sales (Chamberlin, 2013)

Despite their large disposable incomes (termed pocket money), teens often use the mall as a place to hang out and to socialize with 
their friends and to browse, but not to seriously shop (Yarrow and O'Donnell, 2009). Because their behavior is often different from that of adult shoppers, teens pose some unique challenges for mall retailers. Unlike adult shoppers, teens primarily shop with friends (59 percent), and they shop as often as they can; they typically stay at the mall longer than adult shoppers and they tend to be more brand-conscious (Tootelian and Gaedeke, 1992; Haytko and Baker, 2004). Teens' behavior also differs from adults in terms of their interpersonal interactions with retailers. Teens are less likely to seek assistance from salespeople and there is some evidence that teens may actually go out of their way to avoid interacting with salespeople because they feel pressured (Mallalieu and Palan, 2006). For many retailers whose sales strategies are based on increasing UPTs (units per transaction) and SPTs (sales per transaction), teens' avoidance behavior and fickleness may make them a more difficult group to sell to.

Forum mall executives think of teen shoppers not as potential teenagers, but rather as individuals who, because they are hanging out with their friends, make it difficult for "real" teenagers to shop (Chang, 2004). Many malls across Bangalore have tried to lure teens by different retail formats. Given the importance of the teen market and the fact that teen shoppers spend so much time at the mall, retailers and teens must find ways to successfully cope with each other and co-exist at the mall. This research examines the perception and to some extent relationship between retailers and teen shoppers. It seems appropriate given that there appears to be perception gap on both sides of the relationship that the retailerteen dyad be explored from both perspectives in terms of how each feels about the other and how this affects the retail format interaction. Specifically, we explore with retailers how they perceive about teens' behaviors, and how they interact with teen shoppers.

Mall Retailers in the study expressed slight apprehension with teen shoppers arising from instinctive behavior, and to accept assistance. Retailers attempt to deal with these issues at both the individual and the corporate level. Teens' negative views of retailers stem from being ignored, treated as incompetent, and treated with suspicion. Teens also indicated that retailers attempt to 
manipulate and persuade them and teens have developed various strategies to cope with this.

\section{Methodology}

\section{Sample}

In order to gain insights from retailers about teen shoppers, a convenience sample of retailers was obtained by asking sales associates and store managers working across a broad range of retailers to participate in the study. Care was taken to include informants from a wide variety of retailers with respect to type of merchandise (clothes, music and videos, books, sports, hobbies, household goods), type of retailer (discount, department, and specialty retailers; national chains and local stores; primarily in suburban mall settings with a few strip mall retailers included), typical target market (teen vs adult), and from Bangalore only. This resulted in a sample of 120 informants (60 percent female) representing 26 different retailers. The interviews ranged from 20 to 40 minutes in length and all informants regularly worked the "shop floor" and regularly interacted with teenagers who frequented the establishment.

In terms of teen shoppers, our sample is comprised of college going students. This age group spends the most of their time at the mall. To collect the data, a convenience sample was obtained of 18 to 23year-olds, ten initial informants provided names of friends for the researchers to contact and those who participated then provided additional names. The total sample comprised of 120 informants. Social status, based on each informant's area of residence, suggested that 20 percent of the sample lived in an area that was predominantly university students who stayed in and around the mall with the remaining local students who stayed in and around the mall within $3 \mathrm{~km}$ vicinity. Finally, we chose to focus on Forum mall as the context because it was the first mall in Bangalore and is a very popular hangout place for the teens.

\section{Procedure}

Data were collected via depth interviews. Given the broad scope of the areas of interest and the desire to capture the thoughts and 
perceptions of both teens and retailers, a qualitative depth interview data collection method seemed most appropriate. Subsequently, a grounded theory approach, which is useful for both theory generation and elaboration of existing relevant theories (Glaser and Strauss, 1967), was utilized to explore the data for themes. Specific topical areas provided a framework for the depth interviews with both retailers and teenagers The interviews with teenagers focused on understanding their perceptions of retailers and how they interact with them. The teen interviews focused on examining how they perceive they are treated by retailers and how they cope with this.

\section{Findings}

\section{Perception of teenagers}

The teens in the sample say that they are almost always ignored by sales associates at forum mall including the occasions when they are actively seeking assistance.

The entire issue of asking for and offering/accepting assistance frustrated both the teens and the retailers in the sample. Teens claim they do not get help even when they want it and retailers indicate that assistance is not wanted and is refused when offered. What is also interesting in the preceding excerpts is the awareness on the part of retailers with regard to teens' sensitivity about shoplifting. Teens in the sample clearly felt that retailers were suspicious of them, did not trust them, and kept too close an eye on them, which they found frustrating.

The salespeople all just tend to follow you around the store because they always think you are going to steal or something.

Clearly, teens seem to be sensitive to the fact that they are often watched closely and they feel this is unfair, however, retailers forum indicated that often it is corporate policy that dictates how teen shoppers or more specifically groups of shoppers are treated.

\section{Younger is better according to teens}

Teens seem to agree that the age of the sales associate is something that makes them feel more welcome. If they are salespeople in their twenties or they are still a teenager, they act totally normal. They 
will make jokes; they'll be funny, they just act like they are part of the teenage group.

The teen informants definitely seem to perceive younger salespeople to be more trusting of teens, more helpful, friendlier, and more likely to understand what teen shoppers want and how they feel. This was the only consistent issue relating to interacting with salespeople that the teen informants mentioned that made them feel more comfortable, and as evidenced by the retailer excerpts, retailers seem to be very much aware that teens are more comfortable with younger associates.

\section{Mall Charm}

The next factor accounted for around $10 \%$ of the total variance explained. Two variables "layout attracts" and "finding product in no time" were found to be significantly loading on this factor and hence the factor was named as "store charisma". The studies conducted by Nor Khalidah (2004), Craik and McKechnie (1977) and Newman and Cullen (2001) also found the layout of the store to be an important variable in determining teenagers' behavior towards a particular retail format. Along with, Tillman (2007) in his study analyzed that finding the right product in the least time was important from teenagers' point of view as this further leads to teenagers' pursuit of fast and motivates them to buy from the same retailer again. However, in the present study, where $77 \%$ respondents were of the opinion that the layout of forum mall does attract them to shop from there, $62 \%$ of the respondents opined that they were able to find the product in no time. Hence, it can be said that layout of the forum mall not only attracts teenagers but also helps them in locating the products in quick time. The implication of the factor is that the forum mall must also concentrate on the layout. Special sections should be allotted to similar types of products. Proper instructions indicating the direction towards a particular section must also be placed. This will help in promoting teenagers' confidence in forum mall and will also lead to positive word- of - mouth. 
V Jaykumar Teenagers Perceptions of Retail Format in Shopping Malls

\section{Credibility}

Approximately, 92\% of the respondents agreed to "buy from the malls in future too". The reasons for agreeing with this assertion seem to be another two variables clubbed in this factor, i.e., "reliability of forum mall as buying source" supported by the findings of Mohd. (2006) and the "availability of the same product" as wanted in the mall. Hence, this factor was been named as "credibility".. Reliability in terms of product quality, payment security and personal information security were found to be most important for customers.

\section{Visual/merchandise Excellence}

Keeping aside the distinguishing features of the forum mall from other formats, i.e., small shops and online, the teenager never forgets to satisfy himself/herself regarding the basic purpose of his/her, i.e., the product. Therefore, besides the above factors, some of the inherent features of the products sold through the forum mall also lure the teenagers to shop from this format. These features are "variety" and "quality" of the products. Hence, this factor was named as "product excellence". Studies conducted by Kunz (2004), Minoo et al. (2000), Raijas and Virpi (2001), Shah and Mrudula (2005), Mohd. (2006) also found "variety" and "quality" to be important variables affecting teenagers' behavior to purchase from organized retailers. However, this factor explained for nearly $9.5 \%$ of the total variance explained. Where nearly all $(99 \%)$ respondents agreed that they were able to find more variety in forum mall, an almost equal number (96\%) of respondents also agreed that the products sold in forum mall are of superior quality than the other formats Therefore, this factor implies that forum mall will have to consistently provide better quality along with variety in future too.

\section{Discussion}

Past research examines what retailers and teenage shoppers think about each other presents only half the picture, relying on either retailer data or teenage data. This study includes data from both retail employees and teenage shoppers, and it goes beyond simply identifying what they think about each other, to examining how they interact with each other. 
First, it is clear that retailers and teens often find various aspects of dealing with each other problematic. Retailers find that teen shoppers can be annoying both behaviorally and because they are often not serious shoppers. In fact some forum mall executives think of teens not as potential teenagers, but rather as individuals who make it difficult for "real" teenagers to shop (Chang, 2004).

Teens seem to experience a certain level of inconvenience as well, either because they feel ignored or the other extreme where they perceive they are being monitored too closely or pressured to buy. Retailers and teens clearly differ in terms of their perceptions with regard to the same issues. Retailers say they try to treat teens how they feel teens want to be treated, yet teens perceive that retailers treat them with less respect than adult shoppers.

The study demonstrates that at least some retail employees struggle with how to interact with teen shoppers. The retailers indicated that they do their best to try to work with teens by treating them within their comfort zone; however because of the nature of teen - in groups, sometimes just browsing and killing time - teens draw more negative attention to themselves and retailers feel driven to keep a closer eye on them. Retailers, for the most part, indicated that teens are viewed as an asset because although they may not spend money every time they are in the store, they do have money, and in the future they will be adult shoppers even if they are disruptive and annoying now.

\section{Managerial recommendations}

The results of this study provide some significant insights for retailers. Most of the retail informants did not report any specific training with respect to interacting with teenage shoppers. The results of this study, however, suggest that providing retail employees with an understanding of teens' behaviors and perceptions might promote more positive interactions with teen shoppers. For example, teens are much more accomplished shoppers - particularly females - than perhaps salespeople give them credit for, which may result in the perceptions that retailers have about teens' competence. Retail employees would benefit from being presented the facts about adolescents' competence. Shop floor employees would also benefit from techniques that 
would communicate to teens that they are not being ignored but at the same time do not communicate sales pressure. Teens respond well to comments and opinions of salespeople of all ages if they perceive those comments to be honest and sincere and not just an effort to sell the product. Role playing these types of situations with actual teen shoppers would help retail employees identify appropriate and effective communication strategies to use with teens.

Dialogues with mall teen shoppers as part of a training process would also be advised as a way of helping retail employees understand how teens think and behave in diverse retail mall settings. Retailers should turn the tables on teens, and instead of giving their opinions to teens, ask the teens for their advice and their opinions about the merchandise.

The findings suggest that it is not a question of whether or not retailers should interact with teens but rather a question of how to interact with them so they do not feel ignored but also not pressured or treated with suspicion. Perhaps laying the ground work for what to expect on entering the store might help alleviate some of the tension. This age group is used to rules and structure but in a environment they seem to be making up their own rules, which are not always in keeping with adult conventions. Retailers could make all the store policies clear to teen shoppers so they know what to expect and what is expected of them. It could be done in a manner that acknowledges and incorporates the way teens like to shop but also lets them know how far they can go. Setting boundaries is something that works well with most teens in other contexts so perhaps a large "RULES" board at the entrance to the store might be effective.

The initial play on words that "rules, might grab teens' attention flowed by a tongue in cheek yet serious style of wording that teens will respect. This is something that requires little cost for management and lays the ground rules for teens. Although this could be perceived as treating teens differently from adult shoppers, it seems clear that their unique behaviors warrant some specific retail strategies. The argument can be made that teens are not fully adult shoppers in their own right in keeping with the broader sociological view of "the being versus the becoming" (Lee, 
2001). Teens are not quite there yet in terms of certain norms and conventions, and they also choose to disregard certain rules, thus management should implement strategies that recognize and address the issues that are problematic that deviate from the norm of adult behavior.

In addition, retailers should review the current strategies they use when teenagers first enter the store. In many single-line teen clothing retailers, the policy is to greet each teenager and immediately tell them what's new, what's on sale, and ask them what they need help with. This immediately puts teens under pressure to interact and probably triggers the use of coping mechanisms. Perhaps a less aggressive strategy would make teens feel more comfortable. A "call button" akin to flight attendant call buttons on airlines is one possible approach. Teens push a button to turn on a green light which signals to a sales associate that the teen needs assistance. By allowing teens to initiate the interaction, they are likely to feel more in control and less pressured. In addition, when a sales associate wants to offer advice or an opinion they should first ask if it is OK to offer an opinion as opposed to providing an unsolicited opinion. Teens in the sample seemed to trust opinions when the teen solicited the opinion as opposed to when the sales associate offered it.

\section{Limitations and future research}

While this study provides a rich understanding of mall retailing ' and teen shoppers' perceptions of each other and how they interact with one another, there are some opportunities to build on this study.

The development of skills related to perception does not stem solely from experience with retail sales encounters. Rather, it stems from accumulated experience with a wide variety of social encounters and social perception episodes that range from advertising and sales to significant others' (e.g. parents, siblings, and friends) perception efforts (Friestad and Wright, 1994). Thus, a much more complex but illuminating direction for future research would be to identify how the breadth and depth of perception episodes converge in the development of teen shoppers' perception knowledge. Finally, it would seem logical that the development of 90 
competence coincides with the development of perception knowledge, thus it would be interesting to more thoroughly examine the relationship between, and the development of, both concepts in shoppers of all ages but especially in teens.

\section{Conclusion}

From the above analysis it can be interpreted that forum mall not only enjoy good reputation in the present times, but also emerge as a major source of teenagers' buyouts in future. The modern day teenagers lay more emphasis on the value for money. However, almost equal weightage is given to comfort and enjoyment while in forum mall. This clearly demands the provision for varying facilities for teenagers which can create a feeling of enjoyment while they are in the mall. Even though people wish to enjoy while but they also care for factors like personal information security and payment security. Hence, they wish to buy from that mall only which is more reliable from these perspectives. Moreover, layout of the mall is also given due weightage, more emphasis on branded products along with variety was also laid. Therefore, it can be concluded that the success of Forum as a mall experience will highly depend on the adaptability of all the above mentioned factors.

\section{References}

Retailing in India | verdict strategic report. (2012, Aug 13). PR Newswire.

Henry, A. (2012). Consumerism...an evolving trend. The Estates Gazette, , 44-47.

Boush, D.M., Friestad, M. and Rose, G. (1994), "Adolescent skepticism toward TV advertising and knowledge of advertiser tactics", Journal of Consumer Research, Vol. 21, June, pp. 16575.

Boyes, M.C. and Chandler, M. (1992), "Cognitive development, epistemic doubt, and identity formation in adolescence", Journal of Youth and Adolescence, Vol. 21, June, pp. 277-304.

Chamberlin, B. (2010), "Free-spending teens return to forum mall", The Los Angeles Times, March 5. 
Mehta, M. (2009, Sep 08). Large format malls to see highest growth in south india. Financial Express

Urquhart, L. (2003, Oct 01). More new shopping malls in store: INDIA: Rising prosperity and a desire for consumer goods are creating a retail building boom, reports lisa urquhart. Financial Times.

Chang, A. (2004), "Forum mall nationwide setting curfews for teens", Associated Press, New York, NY, available at: www.Bangaloretoday.com/news/nation/2004-09-17-teensforum mall_x.htm.

Coleman, R.P. (1983), "The continuing significance of social class to marketing", Journal of Consumer Research, Vol. 10, December, pp. 265-80.

Friestad, M. and Wright, P. (1994), "The perception knowledge model: how people cope with perception attempts", Journal of Consumer Research, Vol. 21, June, pp. 1-31.

Glaser, B.G. and Strauss, A. (1967), The Discovery of Grounded Theory: Strategies for Qualitative Research, Aldine, Chicago, IL. Haytko, D.L. and Baker, J. (2004), "It's all at the mall: exploring adolescent girls' experiences", Journal of Retailing, Vol. 80, pp. 67-83.

Kang, S. (2006), Chasing generation Y, The Wall Street Journal, available at: www.metroparkBangalore.com/press/story/1

Lee, N. (2001), Childhood and Society: Growing up in an Age of Uncertainty, Open University Press, Buckingham.

Mallalieu, L. and Palan, K.M. (2006), "How good a shopper am I? Conceptualizing teenage girls' perceived competence", Academy of Marketing Science Review, Vol. 5, available at: www.amsreview.org/articles/mallalieu05-2006.pdf.

Mediamark Research, Inc. (2004), Teen Market Profile, Magazine Publishers of America, New York, NY.

NPD Group (2010), The NPD Group, Inc., The NPD Group, Inc., Port Washington, NY.

Rawe, J. (2007), "Bye-bye mall rats", Time Magazine, June 28.

Smetana, J.G., Campione-Barr, N. and Metzger, A. (2006), "Adolescent development in interpersonal and societal contexts", Annual Review of Psychology, Vol. 57, pp. 255-84. 
V Jaykumar Teenagers Perceptions of Retail Format in Shopping Malls

Strauss, A. and Corbin, J. (1990), Basics of Qualitative Research: Grounded Theory Procedures and Techniques, Sage Publications, Newbury Park, CA.

Tootelian, D.H. and Gaedeke, R.M. (1992), "The teen market: an exploratory analysis of income, spending, and patterns", The Journal of Consumer Marketing, Vol. 9, pp. 35-44.

Wright, P., Friestad, M. and Boush, D.M. (2005), "The development of marketplace perception knowledge in children, adolescents, and young adults", Journal of Public Policy \& Marketing, Vol. 24 No. 2, pp. 222-33.

Yarrow, K. and O'Donnell, J. (2009), Gen Buy, Jossey-Bass, San Francisco, CA. 